\title{
La máscara culta del folclor
}

\author{
Beatriz MARISCAL HAY \\ El Colegio de México
}

\begin{abstract}
RESUMEN
Al finalizar el movimiento revolucionario mexicano de 1910, intelectuales y creadores buscaron en el arte indígena y popular inspiración y materia para el arte que había de caracterizar al estado moderno mexicano. A pesar del apoyo que tuvo este proyecto, una década más tarde, un grupo importante de creadores que rechazaba el proyecto cultural nacionalista del estado, se propuso eliminar los elementos tradicionales que habían sido adoptados, ya que consideraba que el uso del folclor era incompatible con la creación de un arte verdaderamente moderno. Ello no obstante, el folclor continuó siendo materia de la obra de algunos de los creadores más importantes del momento y tal vez la marca más reconocible del arte moderno hispano americano. Este trabajo está dedicado al estudio de la apropiación de una leyenda maya por parte de escritores que buscaron crear un arte moderno a la par que nacional.
\end{abstract}

Palabras clave: México, folclor, arte moderno.

\section{The educated mask of the folklore}

\begin{abstract}
At the end of the Mexican Revolution of 1910, artists and intellectuals looked at indigenous and popular art for inspiration for the art that would be representative of modern Mexico. In spite of the support that this project had obtained, a decade later, an important group of creators who rejected the government's nationalist cultural project, sought to eliminate the traditional elements that had been adopted, as they considered that the use of folklore was incompatible with the creation of a truly modern art. Nevertheless, folklore continued being a part of the work of some of the most important artists, as well as what is perhaps the most recognizable trait of modern Latin American art. In this essay I look into the appropriation of a Mayan legend by writers who were interested in creating an art that was both modern and national.
\end{abstract}

Key words: México, folklore, modern art.

Al iniciar el siglo XX, un grupo de jóvenes intelectuales, artistas y estudiantes que habían coincidido en la Escuela Nacional Preparatoria, interesados sobre todo en la poesía, la literatura universal y los estudios clásicos, formaron un grupo llamado inicialmente la Sociedad de Conferencias y, a partir de 1909, Ateneo de la 
Juventud, que se oponía al positivismo de la cultura oficial de Porfirio Díaz y propugnaba el estudio de las Humanidades y la reflexión sobre los fundamentos históricos de la cultura occidental.

Pedro Henríquez Ureña señalaba que los ateneistas consideraban que la filosofía oficial era "demasiado sistemática, demasiado definitiva para no equivocarse" y que constituía una opresión intelectual que iba de la mano de la opresión política y económica, de ahí que se hubieran propuesto "leer a todos los filósofos a quienes el positivismo condenaba como inútiles, desde Platón hasta Kant y Schopenhauer". Con ello, señala, "Descubrimos a Bergson, a Boutroux, a James, a Croce"1.

Este grupo heterogéneo que incluía escritores, escultores, pintores, médicos, músicos y arquitectos, varios de ellos profesores universitarios, se propuso forjar un sistema de educación y una cultura nacional y moderna que fueran reflejo fiel de la naturaleza plural y mestiza de la nación mexicana, por lo que no podía dejar de incluir elementos indígenas y populares.

La lucha armada de 1910 terminó por disolver al Ateneo, pero varios de sus miembros, entre quienes se contaban José Vasconcelos, Diego Rivera, Alfonso Reyes, Pedro Henríquez Ureña, Saturnino Herrán, Alberto J. Pani, Martín Luis Guzmán y Federico Mariscal, habían de influir de manera importante lo mismo en el ámbito universitario que en el gubernamental, de manera especial durante los gobiernos post revolucionarios de Venustiano Carranza y Álvaro Obregón. Los postulados ideológicos de la cultura nacionalista post revolucionaria deben buscarse en esos comienzos.

Ya en la segunda década del siglo XX surge en México un nuevo grupo de escritores, artistas y pensadores, conocido como los Contemporáneos, en razón de la revista de ese nombre que fundaron en 1928, que Independientemente de los sentimientos que inspirara en ellos el programa de cultura nacionalista que propugnaba el gobierno post revolucionario, consideraba necesario dar forma a una nueva literatura mexicana independiente de los proyectos estatales.

Ese "grupo sin grupo" como lo llamara Xavier Villaurrutia, formado inicialmente por Jaime Torres Bodet, Carlos Pellicer, Salvador Novo, Bernardo Ortiz de Montellano, Ignacio Barajas Lozano y Enrique González Rojo, era un elenco de individuos -según el propio Villaurrutia- "inconciliable por su alcance y personalidad", pero dotado "de una misma seriedad y conciencia artística de su labor... [que] de manera especial ... sintetizaba en su porción máxima las primeras realizaciones de un tiempo nuevo"2.

${ }^{1}$ Pedro Henríquez Ureña, "La influencia de la revolución mexicana en la vida intelectual de México", en Universidad y educación. Lecturas Universitarias. México: UNAM, 1969, p. 97.

${ }^{2}$ Xavier Villaurrutia, "Carta a un joven (Edmundo Valadés), "Los Contemporáneos por sí mismos”, pp. XI-XII. Citado por G. Sheridan, Los Contemporáneos ayer, pp.13-14. 
Un aspecto de esa "inconciliable" visión artística de los Contemporáneos, tiene que ver con la utilización del folclor como materia del arte moderno que les interesaba crear, ya que mientras que algunos de ellos consideraban que la utilización del folclor los acercaba demasiado al proyecto nacionalista del Estado mexicano, otros, como Bernardo Ortiz de Montellano, pensaban que era importante recuperar la naturaleza mexicana y la cultura de los pueblos indígenas, ya que la cultura y el espíritu indígena poseían la unidad que no tenía "lo mexicano"; lo indígena tenía un alma colectiva que aún no tenía el mexicano que no era indio ${ }^{3}$.

El interés de Ortiz de Montellano por la literatura indígena lo llevó a dedicar la sección "A.B.C." de la revista La Falange -que dirigía junto con Jaime Torres Bodet- a "la literatura del pueblo y de los niños", en ella aclara su postura frente a la utilización del folclor:

No pretendemos solamente realizar una labor folclórica, sino presentar, unida a la corriente del pensamiento de un país o una época, la obra preciosa del pueblo, manifestada en cantos ingenuos pero maravillosos de emoción vital. Así orientaremos hacia ella el pensamiento aristocrático del escritor de fama, cuya contribución puede y debe enriquecer estos veneros que corren como el agua oculta ${ }^{4}$.

En la Revista de literaturas populares de la UNAM, Enrique Flores publicó un excelente artículo que pasa revista a las diversas y a veces encontradas opiniones sobre la utilización del folclor que manifestaron los Contemporáneos ${ }^{5}$, de manera particular Ortiz de Montellano, así como a la que en ese tiempo expusieron los críticos de esa tendencia como Jorge Cuesta, quien en 1932 escribía que el exotismo, el mexicanismo, el nacionalismo y el "revolucionarismo" oficialista de la Revolución mexicana eran "puras formas de misantropía", opinión que comparten algunos de nuestros contemporáneos, como Irene Vázquez y Guillermo Sheridan quien declara que ese "muestreo de lo autóctono" tenía una carga de patriotismo,

3 Bernardo Ortíz de Montellano. La poesía indígena de México, México [Talleres Gráficos de la Nación], 1935. Reed. en Obras en prosa. Recopilación, edc., preliminares, notas e índices de María de Lourdes Franco Bagnouls. México: Universidad Nacional Autónoma de México, 1988, p.446.

${ }^{4}$ La falange. Revista de cultura latina, México $1^{\circ}$ de diciembre de 1922, p. 45. Reed. en La Falange, 1922-1923. México: Fondo de Cultura Económica, 1980, p. 31.

${ }^{5}$ El trabajo de Flores incluye un fino análisis de la poesía "folclorizante" de Ortiz de Montellano. Enrique Flores, "Folclor y decepción, Bernardo Ortiz de Montellano y la literatura popular", Revista de Literaturas populares, UNAM, año 1, núm. 2, juliodiciembre de 2001, pp. 102-134.

${ }^{6}$ Jorge Cuesta. Obras. México: Ediciones del Equilibrista, 1994, vol. 1, p. 173.

${ }^{7}$ Véase La cultura popular vista por las élites: (Antología de artículos publicados entre 1920 y 1952). Introducción y selección de Irene Vázquez Valle. México: UNAM, 1989. 
entre na $\square$ ve y militante", cuya voluntad epidémica llevaba a "la exaltación de la jícara nacional" ${ }^{\prime}$.

Este breve trabajo está dedicado a la manera particular en que Bernardo Ortiz de Montellano integró esa cultura indígena que tanto admiraba en una de sus obras más peculiares y menos estudiada, la pieza de teatro para títeres inspirada en la leyenda maya-quiché de El Sombrerón que se representó en 1930 en el teatro de títeres de la Casa del Estudiante Indígena de México?.

Es importante notar que la leyenda de El Sombrerón no es propiamente un relato de orígenes que nos aclara de dónde surgen los elementos de la naturaleza que nos rodean -el rayo, la lluvia, los astros o los animales- como suele ser el caso de la mayor parte de las leyendas indígenas, sino que pone en juego aspectos más íntimos del ser humano, tales como el deseo de saber y la pasión, así como los problemas que surgen cuando interviene el principal agente del mal, el demonio.

El Sombrerón ha sido registrado en numerosas versiones tradicionales provenientes de la tradición oral maya de México y Guatemala, y de otras partes de México como Veracruz. Tal y como sucede con la literatura que se transmite de generación en generación por vía oral y que se considera un producto comunitario y no de autoría personal, las diferentes versiones presentan numerosas variantes, lo mismo en cuanto a los elementos que se incluyen en el relato, con consecuencias en cuanto al desarrollo de la trama narrativa, como en las diferentes resoluciones al conflicto que representa la lucha desigual entre los humanos y el demonio.

Un elemento particular de la leyenda es la apariencia de su personaje central, el Sombrerón, ya que aparte del gran sombrero de petate con el que se cubre, su forma física es sumamente inestable; cuando se presenta en forma humana, siempre es muy pequeño, tiene la tez obscura de un indio que, en algunos casos, tiene los pies al revés, con lo que puede huir sin que puedan seguir sus huellas (Jalapa); pero puede igualmente tomar la forma de una pequeña pelota de hule que bota y rebota alegremente.

El Sombrerón tiene dos presas favoritas: los hombres que se preocupan por el saber, a quienes aleja de sus estudios y discusiones filosóficas para que se conviertan en Sombrerón, y las jóvenes de cabellos largos en las que puede engendrar un hijo.

Cuando su meta es atraer a un hombre sabio, se cuela a sitios en los que los libros y la búsqueda del conocimiento son importantes, tales como bibliotecas y conventos. Después de deshacerse de los libros o de eliminar en algún estudioso el interés por el conocimiento, su víctima lo sigue y abandona su morada.

${ }^{8}$ Guillermo Sheridan. Los contemporáneos ayer. México: Fondo de Cultura Económica, 1985, p. 189.

9 Así lo registra la edición de esta obra que se publicara en la Editorial La Estampa Mexicana en 1946, ilustrada con grabados originales de Alfredo Zalce. 
Si lo que busca es engendrar un hijo, el Sombrerón dirige su esfuerzo a inspirar pasión en mujeres jóvenes. Para ello canta al pie de su ventana, acompañado de un guitarrón y, al amparo de la oscuridad, entra en casa de la joven y la impregna, a menudo sin que ella se dé cuenta. La juventud y belleza de las mujeres que atrapa el Sombrerón están señaladas por su largo cabello. Después de que el Sombrerón asegura en ellas su linaje, deja como señal el largo cabello de la joven -como sabemos símbolo de la sexualidad femenina- o bien enredado, o bien trenzado de manera peculiar.

Como suele suceder con este tipo de relato tradicional, sus transmisores proponen soluciones al peligro que representa el Sombrerón, las que recaen en el padre de la agraviada. Si el padre se entera de lo sucedido cuando ya ha sido seducida la joven, busca neutralizar los efectos de la posesión demoniaca cortándole el cabello y llevándola a la iglesia; si tiene la suerte de haber sido avisado de antemano por noticias de otros casos de jóvenes seducidas por el Sombrerón, el padre corta el cabello de la joven ANTES de que el Sombrerón se apodere de ella. Estas soluciones implican la posibilidad de que los humanos se defiendan de las fuerzas del mal.

En contraste, cuando se trata de la seducción de un hombre de saber que va a ocupar el lugar del Sombrerón-demonio, no hay propuesta de solución; contra el atractivo del mal es inútil luchar.

Estos elementos y otros más que sería demasiado largo de enumerar se encuentran en una versión bilingüe, tzotzil-castellana, publicada en el año 2000 en un hermoso libro que lleva el título de El sombrerón. jSemet Pixol, traducido e ilustrado por su autor, el indio maya tzotzil Mariano López Calixto Méndez ${ }^{10}$. Me interesa comentar esta versión pues representa una modalidad particular de apropiación del folclor que constituye un punto intermedio entre la literatura tradicional y la culta.

En su relato, además de al acecho a los humanos por parte del Sombreróndemonio, Mariano López dedica una parte importante del relato a los problemas de los habitantes de la zona maya de Chiapas en la que vive, tales como el abuso de los enganchadores, que con engaños atraen a los trabajadores a las fincas del Soconusco. El personaje central es un indio chamula que, engañado por un enganchador, va en busca de trabajo a la finca llamada "La Esperanza". En ella sufre toda clase de abusos y vejaciones por parte de inhumanos capataces: "En su galera sólo vio enfermos el primer día, tirados sobre tablas respirando el olor insoportable de orines y mierda", además de que incurre en grandes deudas en la tienda de raya, por lo que decide huir e intentar regresar a su casa. En el camino se encuentra con el Sombrerón quien le ofrece ayudarlo, lo que le produce bastante

${ }^{10}$ Mariano López Calixto Méndez. El sombrerón. jSemet Pixol, México: Universidad Nacional autónoma de México, 2000. 
desconfianza, pero el Sombrerón efectivamente lo libra de peligros y lo salva de morir de sed y hambre en el camino, asegurándole que no tiene nada que temer ya que ha sufrido demasiado en manos de capataces y finqueros. Después de numerosas aventuras, el indio chamula se libra del maleficio del Sombrerón gracias a que reza una oración al tiempo que fuma "pilico" una mezcla de tabaco, ceniza, ajo y limón que sirve para alejar las fuerzas del mal: "cada día avanzaba hacia su paraje, muy contento; por fin llegó a su casa". Finalmente a quien atrapa el Sombrerón no es al protagonista sino al hijo del dueño de la finca, significativamente un extranjero alemán.

El culto indio bilingüe, nos ofrece un complejo relato que incluye elementos de la leyenda de El Sombrerón, pero que al aparecer enriquecido con numerosas secuencias narrativas que dan más importancia a la exposición de los abusos por parte de enganchadores, capataces y finqueros de los que son víctimas los trabajadores del campo en el Soconusco, que a la atracción fatal que ejerce el Sombrerón, el relato ya no es fundamentalmente una leyenda sobre seducción, sino una historia de castigo y vindicación de los trabajadores impotentes frente a los explotadores de su trabajo, al quedar desplazada la posesión demoniaca hacia el dueño de "La Esperanza" cuyo hijo es quien cae víctima del Sombrerón.

Este tipo de reelaboración, a pesar de ser producida por una persona que pertenece a la comunidad tradicional, un indio tzotzil que seguramente escuchó la leyenda de algún otro miembro de su comunidad, tal vez su propia madre o abuela, y que participa de la cultura que recrea esos relatos como parte de su saber tradicional, ya no es un texto tradicional, capaz de ser memorizado y transmitido por vía oral como parte de la cultura comunitaria.

Con su nueva máscara, la leyenda del Sombrerón ha perdido el carácter colectivo y abierto propio de los textos tradicionales y se ha convertido en un texto "de autor", un producto individual cuya intención estética, y la fijeza que le da la letra impresa, lo extraen del ámbito del folclor y lo integran en el de la literatura culta.

Otra elaboración importante de El Sombrerón es la que publicara Miguel Ángel Asturias en 1930 en sus Leyendas de Guatemala ${ }^{11}$.

No hay tiempo para detenerme demasiado en esta extraordinaria reelaboración de El Sombrerón, pero si quiero apuntar que Miguel Ángel Asturias, quien la conocía por vía oral ya que sus Leyendas de Guatemala están dedicadas: "A mi madre, que me contaba cuentos", nos presenta la leyenda con un ropaje tradicional que no escapa de la marca del narrador culto. En el inimitable estilo de sus novelas, que ha sido calificado como poesía épica, nos relata la caída de un monje en manos del Sombrerón quien convertido en pelotita de hule, se cuela por la ventana del

${ }^{11}$ Miguel Ángel Asturias. Leyendas de Guatemala. Buenos Aires: Editorial Pleamar, 1949. Todas las citas de esta obra corresponden a esta edición. 
convento y atrae con su alegre rebote al religioso que abandona el convento y el mundo del quehacer artístico y de las disquisiciones filosóficas y religiosas que eran la principal actividad de los monjes.

A pesar de que en su relato imita ciertos recursos propios de los relatos tradicionales, tales como la repetición de vocablos y de frases, importante para la memorización de la que dependen estos relatos para su existencia: "Y era de ver y era de oír y de saber las discusiones en que por días y noches se enredaban los más eruditos...", palabras con las que inicia igualmente el siguiente párrafo: "Y era de ver y era de oír y de saber la plácida tertulia de los poetas..."; el lenguaje erudito que utiliza: "el dulce arrebato de los músicos y la inaplazable labor de los pintores, todos entregados a construir mundos sobrenaturales con los recados y privilegios del arte"12; y la fina ironía que surge desde la primera línea de su relato: "En aquel apartado rincón del mundo, tierra prometida a una Reina por un Navegante loco", apuntan a una creación indiscutiblemente de carácter culto que sirve al galardonado escritor guatemalteco para recuperar la memoria de los indígenas de su amada Guatemala, al tiempo que le permite repudiar los abusos y engaños con los que se pretendió justificar la colonización y cristianización de los indios americanos, composición que llevó a cabo Miguel Ángel Asturias al tiempo que participaba en la traducción del Popol Vuh, obra central de la cultura quiché y los Anales de los xahil, de los indios cakchiquiles ${ }^{13}$.

Estos sentimientos nacionalistas centrados en la recuperación de las tradiciones indígenas, como ya habíamos apuntado, llevaron a Bernardo Ortiz de Montellano a tomar la leyenda de El Sombrerón para crear una obra dramática que se acercara al mundo indígena por el tema y por la forma. Al tratarse de una pieza con títeres, rescataba, además de la leyenda, los títeres de barro que había visto en el Museo Nacional, títeres que formaban parte de la cultura indígena precolombina, como lo había leído en las páginas de La historia verdadera de la conquista de la Nueva España de Bernal Díaz del Castillo: “...porque algunos de ellos (los indios) son cirujanos y herbolarios y saben jugar de mano y hacer títeres" $"$.

Ortiz de Montellano, en su proyecto de recuperación folclorista de tonos culteranos y simbolistas, pretendía con El Sombrerón crear una pieza de teatro que alcanzara, como proponía en ese tiempo el director, productor y teórico del teatro E. Gordon Craig ${ }^{15}$, "una categoría artística pura" ya que en el teatro de títeres la

${ }^{12}$ Leyendas, p. 50.

${ }^{13}$ Véase Miguel Ángel Asturias. Paris 1924-1933. Periodismo y creación literaria. Edc. crítica de Amos Sagala. Paris: Université Paris X, 1988.

${ }^{14}$ Bernal Díaz del Castillos. Historia verdadera de la conquista de la Nueva España. Edc. de Miguel León Portilla, Madrid: Historia 16, 1984, cap. CCIX.

15 El inglés Edward Gordon Craig era editor de The Mask, la primera revista internacional de teatro. 
totalidad del universo escénico: la obra, el trabajo de los actores y la puesta en escena están puestas totalmente en manos del verdadero autor, que debía ser no el director, o el autor, o el actor, o el pintor de decorados y trajes, sino la unidad de todos esos elementos ${ }^{16}$. Este ideal, nos asegura, podía corresponder al teatro de títeres, ya que éste no dependía del gesto (la actuación) de los actores ${ }^{17}$.

La obra comienza con la aparición en escena de una máscara, sin cuerpo que la sustente: es el diablo -Sombrerón, espíritu que está oculto en la tierra-. La máscara informa al público que acaba de quemar la última biblioteca, las biblias y los libros de demonólogos. A pesar de que la ciencia y las costumbres han evolucionado y ya no lo necesitan ni la Celestina ni el doctor Fausto, sigue viviendo y utiliza máscaras, además de que hace juegos de manos y escamoteos. Finalmente, aconseja a los hombres que sigan creyendo en él y sus numerosas máscaras, en los sueños, en los esfuerzos de los poetas y en las leyes de los hechiceros más que en las leyes de los hombres.

La pieza tiene tres escenas y tres personajes además del Sombrerón y su "abuelo", El espíritu de la tierra: una mujer indígena, su hijo y su esposo. En la primera escena, la mujer y su hijo discuten, mientras el hijo termina de afilar su machete, sobre los peligros de permanecer afuera de su choza ya que oscurece y el Sombrerón está al acecho; pero a pesar de que se resguardan en la choza, el Sombrerón se cuela en ella como serpiente, se enrosca ante el fuego y "descansa en el hueco imperceptible de la sombra de la mujer". El padre regresa y en el camino se enfrenta al Sombrerón, lo golpea con el hacha pero no puede hacerle daño pues es como de hule y escapa. La mujer le asegura que solamente vio al Sombrerón y de su seno cayeron dos niños que vuelan convertidos en blancas palomas.

En la segunda escena, que tiene lugar en el bosque, el autor aprovecha el diálogo entre la madre y el hijo para incluir un cuento tradicional que explica por qué las serpientes se comen a los sapos y las águilas a las serpientes. En la oscuridad aparece nuevamente el Sombrerón quien dice palabras de amor a la mujer y amenaza a los leñadores que regresan de cortar ceibas y zapotes, ya que son, nos dice, los enemigos de la tierra.

En la tercera escena aparece el escenario dividido en dos partes, una representa el bosque y otra el inframundo en el que habita el Sombrerón que aparece remendando las alas de un murciélago y habla con el espiritu de la tierra, su abuelo. El leñador y su hijo introducen un enorme tronco en el hueco de la tierra por el que han visto al Sombrerón, con la idea de destruirlo. El espíritu de la tierra le aconseja al Sombrerón que cuando lo hagan, lance un grito inmortal para que crean que ha

${ }^{16}$ Estas observaciones acompañan el texto de El Sombrerón que publicara primero en la revista Contemporáneos, $\mathrm{n}^{\circ} 32$, enero de 1931, pp. 71-96, e incluyera posteriormente en $L a$ poesía indígena de México. México: Talleres Gráficos de la Nación, 1935, pp. 67-83.

${ }^{17}$ Obras en prosa, p. 165. 
muerto. Al caer el tronco, tiembla la tierra y aparecen unas enormes hormigas que cargan pedazos del Sombrerón que éste ha preparado para que se convenzan de que tienen pruebas de su muerte.

La simulación de la muerte del Sombrerón en manos de los hombres que: "quieren descubrirlo todo: lo que está detrás de la jícara del cielo y lo que está esparcido y ardiente en el corazón de la tierra...", termina con el triunfo pírrico de los leñadores que no sólo se engañan en cuanto a su capacidad de destruir al Sombrerón sino que pierden al tigre, símbolo de los animales que dan vida a su entorno: "Y entonces el tigre estaba pasando, muerto, por delante de ellos". Cae el telón.

El esfuerzo de Ortiz de Montellano por dar el lucimiento propio de la alta cultura a la leyenda tradicional maya quiché de El Sombrerón, animado por las teorías teatrales de vanguardia que consideraba culminarían con el teatro de títeres, un teatro sin actores, dio como resultado un interesante experimento de teatro simbolista con tema indígena. Pero a pesar de inspirarse en una pieza importante del folclor indígena que tanto apreciaba, de incluir en ella otros cuentos tradicionales y conceptos propios de la cultura indígena mexicana, su reelaboración de la leyenda en un lenguaje culto, con su manipulación y yuxtaposición de elementos tradicionales diversos, no solamente está, como hemos podido constatar, bastante alejada del folclor que la inspira, sino que la ha convertido en un texto tan individual, que difícilmente podría hacerlo suyo el pueblo que mantiene la leyenda viva en la memoria colectiva.

El Sombrerón puede manifestarse por medio de numerosas máscaras, a fin de cuentas, las fuerzas del mal tienen innumerables rostros, pero su leyenda, el folclor, sólo permanece vigente en su propia cultura, en la tradición, no puede mantenerse vivo tras las máscaras cultas que le han impuesto los escritores que se apropian de él. 